\title{
\#WomenInScience: Ngày Quốc tế Phụ nữ trong Khoa học (11/2)
}

Hồ Mạnh Toàn

AISDL

Hà Nội, ngày 12 tháng 2 năm 2020

AISDL (12-02-2020; https://sc.sshpa.com/post/5623) - Kể từ năm 2015, ngày 11 tháng 2 hàng năm đã chính thức được Đại hội đồng Liên hiệp quốc công nhận là Ngày Quốc tế Phụ nữ trong Khoa học. Sự kiện này được UNESCO và UN Women kết hợp cùng với các cơ quan đối tác tổ chức trên toàn thế giới nhằm khuyến khích sự tham gia của phái nữ trong khoa học.

Trên Twitter, hashtag \#WomenInScience hoặc \#WomenInScienceDay đã được sử dụng để truyền tải các thông điệp ý nghĩa trong ngày này. Trang tin lớn National Geographic đã tweet lại những bài viết hay trong số báo đặc biệt về ảnh hưởng và vai trò quan trọng của phụ nữ "Women: A Century of Change."

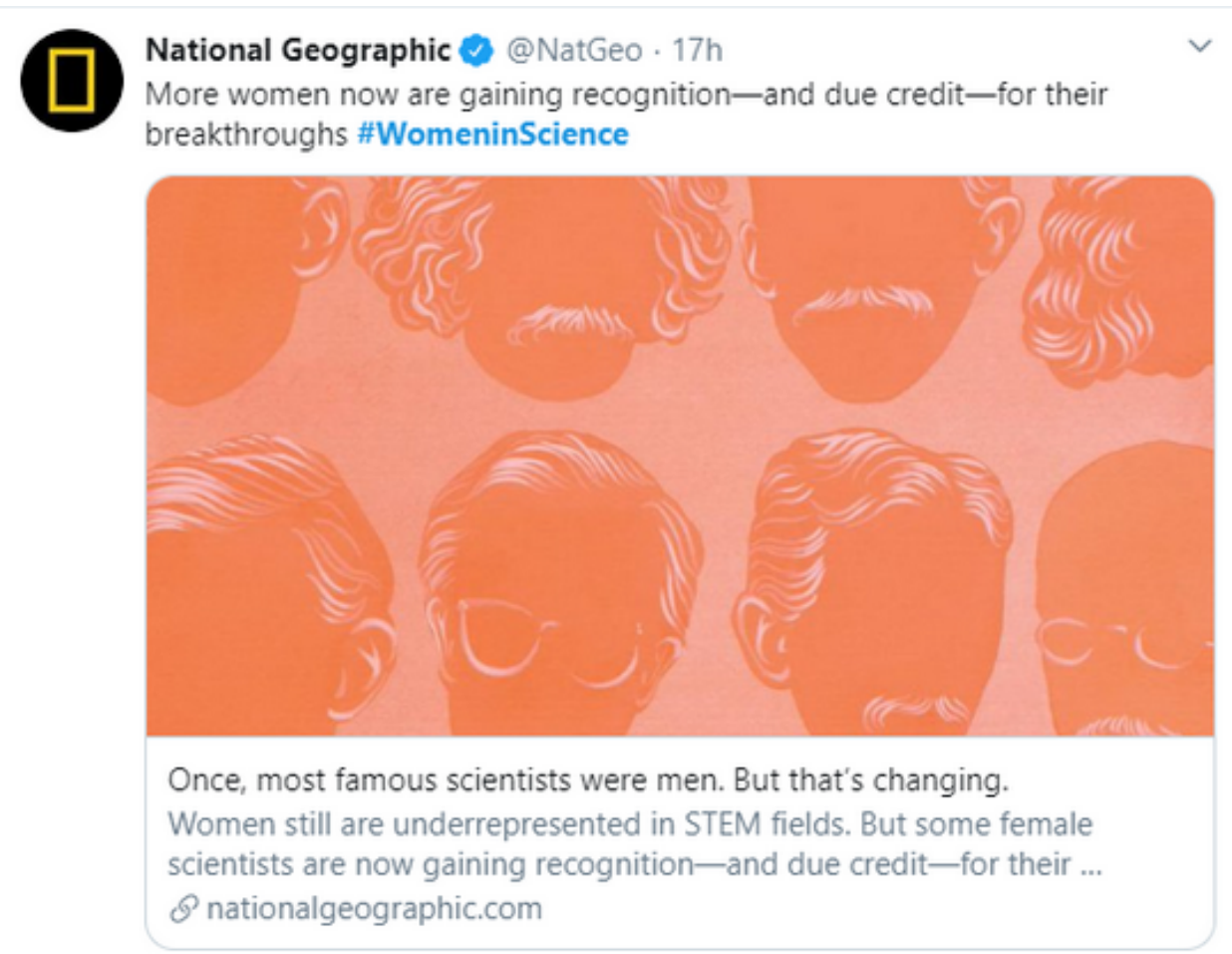

Women: A Century of Change

Trong khi đó, UN Women nhắc lại về một người đầu tiên đạt 2 giải Nobel ở hai ngành khác nhau: Marie Curie. 


\section{UN Women @UN_Women.19h}

On \#WomenInScience Day, get inspired by the life of Marie Curie,

the 1st woman to be awarded a \#NobelPrize,

the 1 st individual to be awarded 2 Nobel Prizes, and

the only individual with 2 Nobel Prizes in two different scientific categories!

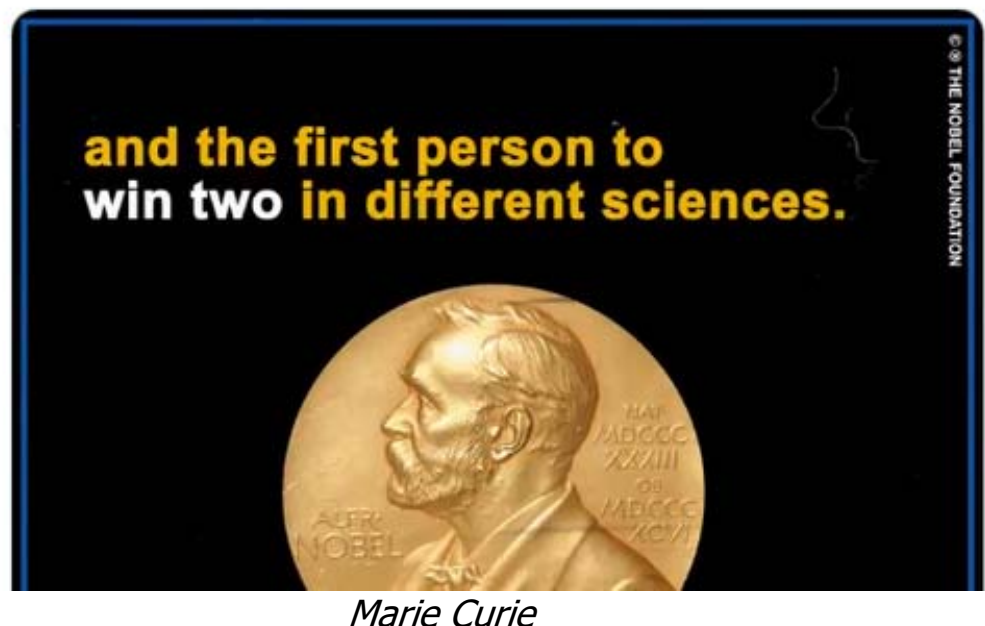

Twitter Cosmic Database lại tweet về Caroline Hershel, nhà thiên văn học nữ đầu tiên, người phụ nữ đầu tiên phát hiện ra một sao chổi, và là người phụ nữ đầu tiên được trả tiền cho công trình khoa học của mình.

cosmic database @cosmicdatabase.19h

Caroline Herschel

- 1st woman astronomer.

- 1st woman to discover a comet

- 1st woman to be paid for scientific work.

- In total she discovered 14 new nebulas, 8 comets and added 561 new stars to Flamsteeds Atlas.

\#WomenInScience

\section{Caroline Herschel}

(1750 - 1848)

Astronomer

Caroline Herschel was the sister to William, with whom she worked for all of her career. She is the first woman to be paid for her scientific contributions, the first to be awarded the Gold Medal of the Royal Astronomical Society, and the first to discover a comet. Together with her brother, they cataloged more than 2000 nebulae and star clusters.

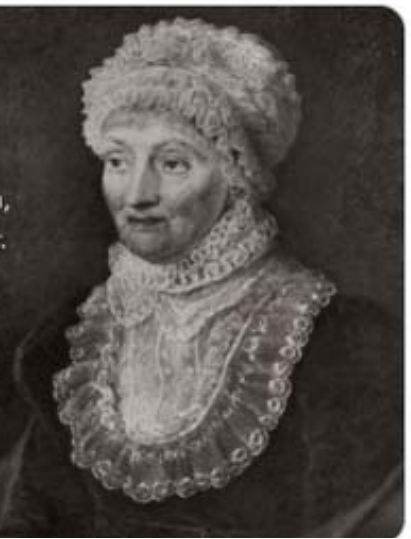

\section{Caroline Hershel}


Và rất nhiều các phòng lab, cơ sở nghiên cứu, và cá nhân khác vinh danh những người phụ nữ đang cống hiến hết mình cho khoa học.
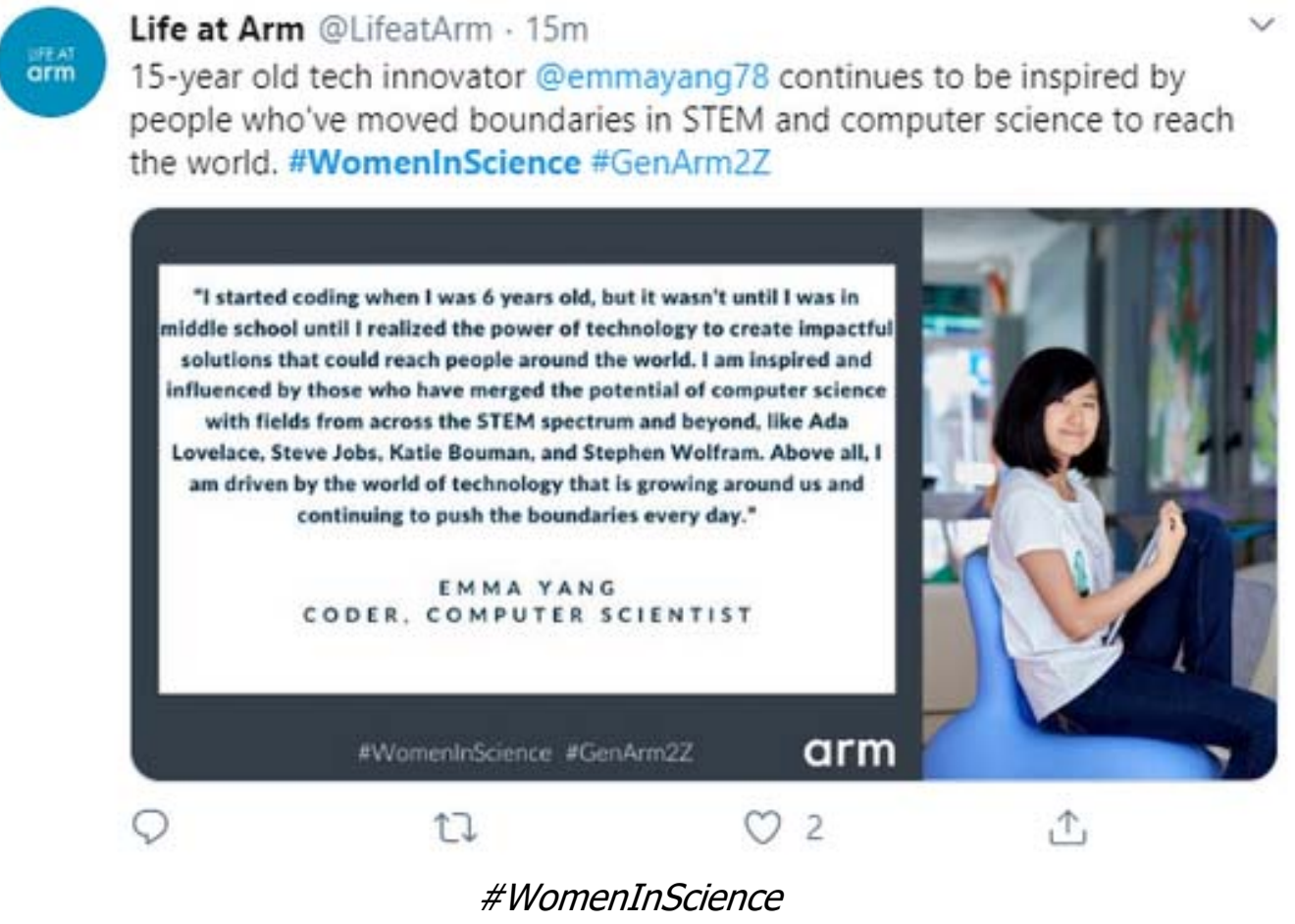

Dù không dự tính trước, nhưng tình cờ trong ngày 11-2-2020 này, EASE Vietnam Regional Chapter đã đóng góp bản dịch tiếng Việt chính thức của bộ hướng dẫn SAGER về giới và giới tính trong nghiên cứu khoa học [1].

Hiện nay, sự phát triển của khoa học Việt Nam, đặc biệt là khoa học xã hội và nhân văn, cũng có sự đóng góp rất lớn từ phái nữ: họ chiếm tới $42 \%$ tổng số tác giả của toàn ngành. Có thể nói, phát huy năng lực và sức mạnh nghiên cứu của phái nữ sẽ giúp thúc đẩy quyền phụ nữ và giúp khoa học Việt Nam mạnh thêm [2].

Tại phòng lab AISDL, chúng tôi cũng luôn cảm ơn sự đóng góp không mệt mỏi của nữ giới. Ban đầu là Vương Thu Trang và Nguyễn Tô Hồng Kông [3], trong suốt hành trình nghiên cứu. Mới đây, sự tham gia và đóng góp của những người bạn nữ khác: Nguyễn Thanh Thanh Huyền, Nguyễn Thanh Dung, Nguyễn Thanh Nhàn, Lương Anh Phương, Nguyễn Thị Linh, Lê Thị Kim Ngân [4], Hồ Hoàng Anh [5], Nguyễn Phúc Khánh Linh [6], và Phạm Thanh Hằng [7], cũng tiếp tục khẳng định vai trò quan trọng của một nửa thế giới trong một nghề vốn hay được xem là thế mạnh dành cho nam giới này. 


\section{*Tài liệu tham khảo:}

[1] Ho MT, Nguyen TL, Pham TH, Vuong TT. (2020). The SAGER Guidelines Vietnamese translation. EASE. URL: https://ease.org.uk/wp-content/uploads/2020/02/SAGER-VNv1.pdf

[2] Vuong QH (2019). Breaking barriers in publishing demands a proactive attitude. Nature Human Behaviour 3(10): 1034. doi:10.1038/s41562-019-0667-6.

[3] Ho MT, Nguyen THK, Vuong TT, Nguyen MH, Tung HM. (2019). To walk on the Penrose stairs of science. Nature: Behavioural and Social Sciences. URL:

https://socialsciences.nature.com/users/301097-ho-manh-toan/posts/54541-to-walk-onthe-penrose-stairs-of-science

[4] Huyen NTT, Dung NT, Nhan NT, Luong AP, Linh NT, Le TKN, Ho MT. (2020). KHXH\&NV: Hơn một thập kỷ tăng số lượng và chất lượng công bố quốc tế. Khoa học và Phát triển. URL: http://khoahocphattrien.vn/chinh-sach/khxhnv-hon-mot-thap-ky-tang-so-luong-vachat-luong-cong-bo-quoc-te/20200113023839782p1c785.htm

[5] SSHPA. (2020). Tôi là SciComm: 47 giây thôi mà. EASE Vietnam SciComm System. URL: https://sc.sshpa.com/post/5616

[6] Nguyen PKL. (2020). Biên tập học thuật chuyên nghiệp cùng EASE. EASE Vietnam SciComm System. URL: https://sc.sshpa.com/post/5611

[7] Pham TH. (2020). Đã có bản tiếng Việt của Bộ hướng dẫn SAGER về giới và giới tính trong nghiên cứu. Khoa học và Phát triển. URL: http://khoahocphattrien.vn/khoa-hoc/da-coban-tieng-viet-cua-bo-huong-dan-sager-ve-gioi-va-gioi-tinh-trong-nghiencuu/2020021209364880p1c160.htm 